\title{
Derecho al agua y covid-19
}

\section{Introducción}

Hoy iniciamos la segunda sesión del ciclo de conversaciones organizados por el Centro de Derechos Humanos, «Derechos humanos en tiempos de pandemia». El tema que nos convoca es el derecho al agua, a propósito de la realidad que nos pone de manifiesto la epidemia del covid-19, en que el agua no es accesible a todos los chilenos en cantidad y calidad suficiente para garantizar condiciones mínimas de higiene.

Una de las situaciones más complejas que se ha evidenciado se refiere a la vulnerabilidad que representa no poder garantizar el lavado reiterado de manos con jabón, es decir, no tener acceso a la más simple y efectiva medida sanitaria para evitar el contagio de coronavirus.

La escasez hídrica o sequía que afecta al país se expresa de manera dramática en 137 comunas en que no hay agua suficiente para abastecer las necesidades de consumo humano diarias de la población que allí habita, para bebida, alimentación y saneamiento en la evacuación de orines y excretas. En cifras, son 1.043.557 los habitantes de esas comunas que no pueden siquiera cuidarse lavándose las manos con frecuencia como medida de prevención ante el covid-19.

Para debatir sobre este tema, hoy hemos convocado a tres panelistas de tremenda trayectoria y experiencia en esta materia.

\section{Pregunta 1}

¿Cómo puede garantizarse el derecho al agua para asegurar que las personas tengan acceso real? ¿Cuáles son las obligaciones del Estado en la materia? ¿Cuáles son los mínimos exigibles de acceso, en especial en materia de cantidad y calidad para agua potable $y$ saneamiento, de modo de cubrir las necesidades de consumo humano en forma digna? Como breve referencia de contexto - que los panelistas tienen, pero nuestro público puede que no-sobre el mínimo vital del derecho al agua potable y el saneamiento, existe como antecedente la Resolución 456 del 8 de abril de este año, dictada por la Seremi de Salud de Valparaíso, que oficiaba que se debía asegurar la entrega de un mínimo 
de cien litros de agua por persona en una zona de la región de Valparaíso, por medio de camiones aljibe. Sin embargo, ocho días después se dictó una nueva Resolución 458, del 16 de abril, que dejó sin efecto la primera, sin haber dado a los vecinos acceso a esta agua que se señaló como el mínimo vital para el consumo humano.

\section{Sara Larraín}

Muchas gracias al Centro de Derechos Humanos por la invitación y por organizar este conversatorio.

El acceso al agua es un tema de gran debate ciudadano. Prácticamente todas las semanas hay conversatorios vinculados con este tema por la situación de sequía, pero también porque estamos en un proceso de crisis respecto del marco jurídico, en particular respecto del Código de Aguas y en el contexto del proceso constituyente, en el que es muy importante esta discusión, en la medida en que la sociedad requiere reformular la utilización y el acceso a los bienes comunes.

En la actualidad, existe un marco jurídico en el derecho internacional que se debió haber incorporado hace diez años dentro de la política nacional para asegurar el derecho humano al agua. Si bien se está tramitando una reforma al Código de Aguas -el Boletín 7.543-12, que es una moción parlamentaria del año 2011-, ', que plantea el derecho al agua como un derecho humano que debe ser garantizado por el Estado, la verdad es que estamos atrasados en una década respecto de la resolución de la Asamblea General de Naciones Unidas de 2010, que establece el derecho humano al agua potable y saneamiento como un derecho esencial que permite asegurar los demás derechos.

Esta resolución fue vista y aprobada por la Comisión de Derechos Humanos de Naciones Unidas y establecida como norma vinculante; por lo tanto, los informes de los Estados sobre el ejercicio de derechos o las garantías de derechos humanos deben incorporar la información sobre el acceso al agua potable y al saneamiento de la población.

Hay un segundo elemento que obligaría al Estado de Chile a establecer en la legislación nacional el derecho humano al agua, que es la Agenda 2030 sobre Objetivos de Desarrollo Sustentable. En su Objetivo 6, la Agenda establece el imperativo de concretar el derecho humano al agua potable y al saneamiento para todas las personas en todas las naciones al año 2030.

Por último, está la recomendación de la Organización Mundial de la Salud, que establece que, para mantener la protección de la vida, la higiene básica y la salubridad, cada persona debiera tener un mínimo de cien litros al día, lo que obviamente hoy no

1. Moción que ya fue aprobada en la Cámara de Diputados y las comisiones de Recursos Hídricos y de Agricultura del Senado. Hoy está en trámite final en la Comisión de Constitución de dicha institución. 
se está cumpliendo en cuanto a cantidad, calidad y frecuencia a través del reparto de agua por camiones aljibe. Tampoco corresponde al cumplimiento de la garantía del acceso a agua potable y saneamiento. En Chile, una parte importante de la población tiene problemas de acceso al agua potable en las áreas urbanas concesionadas, cerca de 50.000 hogares, mientras que en otros sectores no concesionados hay más de 130.00o hogares sin agua. En el sector rural hay cerca de 1.700 asociaciones de agua potable rural, parte importante de ellas entre las regiones de Atacama y del Maule, están con problemas de abastecimiento. En la región del Biobío Costa también tienen problemas de acceso al agua potable y algunas comunas están siendo servidas con camiones aljibe, principalmente en poblaciones semiconcentradas y aisladas, aunque en la mayoría de estas últimas no tienen este servicio. En cuanto al saneamiento, hay cerca de 184.00o hogares en áreas urbanas concesionadas sin acceso a alcantarillado, y entre 1.800 .000 y 2.000 .000 de personas en el sector rural no tienen acceso al alcantarillado ni al saneamiento de aguas. Ahí hay un gran desafío, sobre todo en los asentamientos humanos semiconcentrados y aislados.

El desafío de Chile es bastante grande. En los últimos diez años la situación se ha agravado, porque la masificación de la prestación de este servicio a través de camiones aljibe ha aumentado mucho, y además los costos son muy altos. El Ministerio del Interior y los municipios están pagando un sistema muy caro para responder a las necesidades de abastecimiento de agua potable de la población. Habría sido mucho más barato que esos mismos recursos se hubieran utilizado para establecer la infraestructura de los servicios de agua potable rural que faltan y mejorar aquellos servicios rurales incompletos, como el caso del pozo que «quedó colgando» ${ }^{2}$ del que por lo tanto no pueden sacar agua; o bien asegurar el bombeo del agua a la torre a través de equipos solares que no necesitan combustible y son muy baratos de mantener. Es decir, muchos servicios de agua potable rural que son autogestionados mediante administración público-comunitaria están sin agua, o funcionando mal porque no han tenido el apoyo necesario del Estado. Aquí hay un tremendo retraso, que nosotros creemos que no es aceptable, en la medida en que hay fondos en el Ministerio de Obras Públicas, y la verdad es que se podría renunciar a algunos puentes o algunos embalses con el objeto de resolver lo que es primero y lo que debió ser prioritario. Eso no ha ocurrido - y desgraciadamente en gobiernos de todo tipo de ideología- porque hay un retraso fundamental en el ejercicio de este derecho humano, lo cual no es aceptable. Hay que admitir que en el gobierno pasado de la Nueva Mayoría se logró sacar una ley de servicios sanitarios rurales, con el objeto de reconocer a estas organizaciones que en forma voluntaria están a cargo los servicios de agua potable rural. La verdad es que esa ley lleva casi seis años de dictación y aún no tiene reglamento; por

2. La referencia a un pozo de agua que «quedó colgando» significa que al nivel de profundidad del pozo ya no hay agua. 
lo tanto, no se puede implementar y poner en vigencia, lo que perjudica a este sector, que es el que está más atrasado en cuanto al acceso al agua potable y saneamiento.

Es importante tener presente que hasta ahora solo me he referido al derecho al agua potable y saneamiento. Eso no comprende los derechos de subsistencia, es decir, aquellos derechos de los campesinos a acceder a derechos de agua para seguir desarrollando sus actividades agrícolas de subsistencia. Ahí hay otro gran problema, en el que ni siquiera se está respetando el derecho de ese sector campesino a utilizar sus propios derechos, y se ha dado prioridad a sectores de exportación, como las paltas, los olivos, entre otros, a costa de los derechos de los campesinos en las zonas más planas, que tienen sus derechos pero no pueden ejercerlos. Similar situación ocurre en muchos lugares en el mundo indígena, en particular en la zona norte afectada por la escasez de recursos hídricos, producto de la sobreexplotación de acuíferos y cabeceras de cuenca por parte de la minería.

Entonces, hoy tenemos grandes desafíos, y uno de los temas relevantes que se ha evidenciado, a propósito de la pandemia del covid-19, es que hay un déficit respecto de la garantía del derecho humano al agua potable y saneamiento. Esto ha imposibilitado responder a las necesidades de higiene y prevención del contagio del virus, que requiere lavarse las manos en forma reiterada. Tampoco hemos logrado que el gobierno establezca un programa de reactivación que tenga como prioridad la inversión pública en los servicios de agua potable rural que lo requieren, o resolver las carencias de los sectores urbanos concesionados, que hoy no tienen agua potable ni saneamiento.

\section{Ana Lya Uriarte}

Primero, quisiera agradecer al Centro de Derechos Humanos por esta iniciativa.

El trabajo por convertir en el plano internacional $-\mathrm{y}$, en consecuencia, como una obligación de carácter internacional - el derecho humano al agua como derecho humano propiamente tal es un trabajo de larga data. Partió en 1977 con el Plan de Acción de Mar del Plata; después, en 1992, se concretó la Declaración de Dublín sobre el agua y desarrollo sostenible, y luego se avanzó hasta lograr el reconocimiento de este derecho con la Resolución 64/292 de Naciones Unidas de 2010.

Sin embargo, este reconocimiento de la provisión de agua a las poblaciones como derecho fundamental no ha tenido un correlato en la realidad, en términos de que todas las capacidades del Estado y todas las acciones posibles, tanto en el orden constitucional, legislativo, institucional y de gestión, que pudieran haberse tomado para asumir esta tarea no se han verificado en forma íntegra. Incluso para las poblaciones que hoy tienen acceso al agua potable, hay que considerar - como dice Gustavo Durán en un estudio que publicó en 2015 llamado «Agua y pobreza en Santiago de Chile: Morfología de la inequidad en la distribución del consumo domiciliario de 
agua»- que, más que brechas de acceso al agua, existen brechas de consumo en amplios sectores de nuestras sociedades. Es decir, son dos los problemas que tenemos a nivel de población vulnerable o vulnerada: por una parte, los que no acceden al agua y, por otra, respecto de los que acceden, las grandes brechas de consumo existentes. Como señala Durán: «Aparentemente, la ciudad capitalista resolvió el acceso al agua en términos estructurales, distribución y recolección, pero no en términos de equidad, no obstante profundizar en el ámbito del consumo y lo que esto representa para una familia pobre, puede ser otra clave para comprender otras formas de exclusión en la ciudad».

Hago este alcance porque estamos centrados en esta ocasión en el no acceso al agua potable por parte de población vulnerable o vulnerada, pero hay otra dimensión tan importante como ésa, que es la restricción de consumo precisamente para poblaciones que, teniendo el acceso mediante distribución y recolección —o sea, acceso al agua potable y saneamiento-, se ven, no obstante, restringidas en su uso por características estructurales de condición económica o nivel socioeconómico al cual pertenecen, que es otra manera de ocurrencia de una violación o una infracción a obligaciones de carácter internacional respecto del agua.

El derecho al agua está contenido en distintos instrumentos internacionales, que establecen su caracterización y contenido. Estos son: que sea suficiente, el abastecimiento al agua de cada persona que debe ser continuo y suficiente para usos personales y domésticos; tiene que ser salubre, en definitiva, que no ha de contener microorganismos o sustancias químicas radioactivas; han de ser accesibles el agua y las instalaciones de servicio del agua, para todos sin discriminación alguna dentro de la jurisdicción del Estado parte, con accesibilidad física a la estructura y sin discriminación, es decir, nadie puede quedar excluido por su sexo, idioma, religión, opinión política o cualquier otra índole; además, se establece el derecho a la información, pues todos tenemos derecho a solicitar, recibir y difundir información de agua.

Por último, debe ser asequible. ¿Qué significa que sea asequible? Implica que el agua y las instalaciones se encuentren al alcance de todos, económicamente hablando. De nuevo esto nos remite al comentario que hacía recién respecto de que el problema no es solo la falta de acceso: no hay que olvidar el problema de los que sí tienen acceso, pero con una brecha de consumo producto de su vulnerabilidad económica estructural.

El saneamiento es un tema tan importante como el acceso al agua potable y, como ya se dijo, la Agenda 2030 para el Desarrollo Sostenible establece diecisiete Objetivos de Desarrollo. El Objetivo 6 es precisamente el acceso a agua limpia y saneamiento, y dice que la meta a lograr es el acceso a saneamiento e higiene adecuado y equitativo para todos, además de poner fin a la defecación al aire libre, prestando especial atención a las necesidades de las mujeres, las niñas y las personas en situación de vulnerabilidad. Esto último es importante, porque se está configurando a escala interna- 
cional el acceso al saneamiento en un nivel equivalente al del acceso al agua, porque es igual de vulneratoria a la dignidad y posibilidades de vida adecuada tanto la falta de acceso al agua potable o acceso restringido como al saneamiento, que, entre otras condiciones, debe garantizar intimidad y dignidad.

Un punto que quisiera destacar y que tiene relación con la Resolución 456 del 8 de abril de 2020 y que ocho días después fue dejada sin efecto mediante la dictación de la Resolución 458, es que hay una obligación internacional de respetar el derecho humano al acceso al agua potable y al saneamiento, y esta obligación está referida a los Estados parte.

El origen de la primera circular emitida por la Seremi de Salud y que dispuso la entrega de 100 litros de agua diaria respondió a la indicación de la Organización Mundial de la Salud (OMS) en orden a las cantidades adecuadas para un alto nivel de protección a la salud de las personas. Al respecto, acompañamos el cuadro de la OMS (tabla 1). Esta imagen corresponde a la cantidad de agua domiciliaria, el nivel del servicio y la salud.

Tabla 1. Resumen de los requisitos del nivel del servicio de agua para promover la salud

\begin{tabular}{|c|c|c|c|}
\hline Nivel de servicio & Medida de acceso & Necesidades cumplidas & $\begin{array}{l}\text { Nivel de } \\
\text { preocupación } \\
\text { por la salud }\end{array}$ \\
\hline $\begin{array}{l}\text { Acceso básico (la cantidad } \\
\text { promedio no puede } \\
\text { superar } 20 \mathrm{l} / \mathrm{r} / \mathrm{d} \text { ) }\end{array}$ & $\begin{array}{l}\text { Entre } 100 \text { y } 1.000 \mathrm{~m}, 0 \text { de } 5 \text { a } \\
20 \text { minutos de tiempo total de } \\
\text { recolección. }\end{array}$ & $\begin{array}{l}\text { - Consumo. } \\
\text { - Se debe asegurar higiene. } \\
\text { - El lavado de manos y la higiene básica de la } \\
\text { alimentación es posible; es difícil garantizar la } \\
\text { lavandería y el baño a no ser que se practique en } \\
\text { la fuente. }\end{array}$ & Alto \\
\hline $\begin{array}{l}\text { Acceso intermedio (canti- } \\
\text { dad promedio de } 50 \mathrm{l} / \mathrm{r} / \mathrm{d} \text { ) }\end{array}$ & $\begin{array}{l}\text { Agua abastecida a través de un } \\
\text { grifo público, } 0 \text { dentro de } 100 \\
\text { m } 05 \text { minutos del tiempo total } \\
\text { de recolección. }\end{array}$ & $\begin{array}{l}\text { - Consumo. } \\
\text { - Asegurada la higiene. } \\
\text { - La higiene básica personas y de los alimentos está } \\
\text { asegurada; se debe asegurar también la lavandería } \\
\text { y el baño. }\end{array}$ & Bajo \\
\hline $\begin{array}{l}\text { Acceso óptimo (cantidad } \\
\text { promedio de } 100 \mathrm{l} / \mathrm{r} / \mathrm{d} \text { ) }\end{array}$ & $\begin{array}{l}\text { Agua abastecida de manera } \\
\text { continua a través de varios } \\
\text { grifos. }\end{array}$ & $\begin{array}{l}\text { - Consumo. } \\
\text { - Se atienden todas las necesidades de higiene. } \\
\text { - Se deben atender todas las necesidades. }\end{array}$ & Muy bajo \\
\hline
\end{tabular}

Fuente: Guy Howard y Jamie Bartram, «Domestic water quantity, service level and health», Organización Mundial de la Salud, disponible en https://bit.ly/2Decfl5.

La obligación de los Estados de garantizar el acceso al agua potable y al saneamiento conlleva ciertas obligaciones. Significa que los Estados parte deben abstenerse de incidir, directa o indirectamente, en cualquier tipo de actividad que pueda restringir el acceso al agua potable en condiciones de igualdad. Tienen también la obligación de abstenerse de inmiscuirse en forma arbitraria en los sistemas consuetudinarios o tradicionales de distribución de agua, en lo fundamental en la perspectiva 
de las costumbres y usos de los pueblos originarios, y deben abstenerse de cualquier conducta que pueda significar reducir o contaminar en forma ilícita el agua con desechos provenientes de instalaciones pertenecientes al Estado o mediante el empleo o ensayo de armas, por ejemplo.

El Estado, en esta materia, también tiene obligación de proteger. Esta obligación le exige que impida que terceros menoscaben en modo alguno el disfrute o el derecho al agua. Este punto se relaciona con la forma en que el Estado debe conciliar el desarrollo de actividades económicas, como el desarrollo de la agricultura frente a la provisión de agua a las comunidades, o el desarrollo de la minería frente a la disponibilidad y aprovisionamiento a comunidades. Ejemplo claro en este sentido es el caso de las comunidades de pueblos originarios en el norte de Chile.

Cientos de miles de personas en el territorio del país sin acceso a agua potable directo, cientos de miles de personas en nuestro país sin acceso a saneamiento y cientos de personas en nuestro país que en medio de una pandemia tienen restringido el consumo por condiciones económicas - que es la brecha de consumo, como la denominaba Durán-, o que derechamente no tienen acceso al elemento agua, en circunstancias de que es una de las maneras de prevenir el contagio. Pandemia que, entre otras cosas - debo remarcarlo, porque tiene una vinculación directa con el tema que estamos tratando, cuando vivimos una crisis hídrica-, reconoce su origen en acciones del ser humano, es decir, factores de carácter antropogénico como el cambio climático, por haber forzado las condiciones planetarias de la naturaleza. Las pandemias - de la que el covid-19 no es excepción - tienen su origen en el mismo punto: en acciones humanas, pues ha sido tal la presión que el ser humano ha ejercido en los hábitats naturales, al extender la frontera urbana y restar terreno a los hábitats naturales, que se ha propiciado el contacto directo entre animales silvestres con domésticos que han transportado el virus al humano, o derechamente de animales silvestres en contacto con seres humanos.

\section{Samuel Yupanqui}

Imaynalla kashankichis wayqeykuna, panaykuna. Los saludo, hermanos, hermanas. Muy contento de esta invitación, de poder debatir un tema tan relevante. Es un orgullo y un honor poder hablar hoy, en representación de los pueblos originarios, estos temas que complejos, delicados y que significan también tanto dolor.

Creo que mi rol desde la dirigencia indígena tiene que ver con situar cómo este problema nos afecta a nosotros los pueblos originarios y cómo lo entendemos. En esa lógica, creo que también es muy importante retomar lo que ya se ha dicho y se mencionó: no es posible analizar este tema al margen del estadillo social, de las demandas sociales y de lo que también expresó la misma hermana Sara, que el Estado o las formas de solucionar estos problemas recaen siempre en las soluciones que parecieran 
más caras, en las soluciones más costosas para todos en cuanto vidas y también en términos económicos, y eso nos invita de inmediato a pensar cuáles son las lógicas de estructuración desde las que se ejerce este poder que nos somete a nosotros. El poder del Estado, el poder colonial que todavía sigue vigente en nuestras vidas.

Estamos en un proceso de cambio, en que la ciudadanía ha demandado este despertar de conciencia sobre el uso de los recursos, de los mal llamados «recursos naturales», porque desde nuestra cosmovisión no son recursos. Estamos ante un Estado que no pone su énfasis, su entendimiento, en lo humano; y si no lo pone en lo humano, en el desarrollo de lo humano, menos lo va a poner en el desarrollo de la naturaleza. Entonces, aquí se conjuga una gravedad que es muy fuerte: que nosotros, hablando el mismo idioma, técnicamente español, haciendo demandas sociales sobre nuestro derecho al agua, y no se nos escucha, mucho menos se va a escuchar a otras formas de vida, otras con las que compartimos. La naturaleza, los animales, todo se ve afectado con estos problemas que se vienen arrastrando por el uso y explotación indiscriminada del agua, que no se ha entendido como un bien de consumo humano. Bien podríamos apegarnos a lo que han establecido los tratados internacionales sobre el derecho al agua como un derecho humano, pero sabemos que, lamentablemente, en nuestra realidad pareciera que los derechos internacionales pasan a ser menoscabados, soslayados por decretos. Cuestión muy curiosa: los tratados internacionales deberían afectar la institucionalidad desde la Constitución hacia abajo, pero son siempre decretos los que terminan tomando las decisiones sobre nuestros derechos. En esta lógica, creo que la forma en que el Estado debería garantizarla es a través de esta iluminación que nos dan en cierta medida los derechos internacionales. Lamentablemente, como expliqué, no se puede llegar a ello porque no está la voluntad, porque el Estado no valoriza los derechos de los pueblos originarios, sus derechos consuetudinarios, ni los derechos de la naturaleza, sino el derecho de la explotación, del uso de los privados, los monocultivos que van en desmedro del uso de las comunidades en el agua, de un uso democrático y del entendimiento de que todos somos parte de un ecosistema y podríamos tomar decisiones en torno a ello. Por lo general éstos se excluyen en favor de unos pocos y de legislaciones que están hechas para unos pocos, para nuestras élites, para el desarrollo del libre mercado.

En cuanto a los temas de los decretos a los cuales se hace referencia, no creo que pueda agregar mucho más de lo que se ha dicho. Pero sí cabe la reflexión de lo importante, que es valorar el agua y que nuestras poblaciones andinas en muchas partes siempre han vivido con escasez hídrica. Entonces, me pregunto: ¿son cien litros? ¿Son mil litros? ¿Cuántos litros son? Estamos en una situación tan grave que probablemente en algún momento tengamos que adecuarnos a vivir con mucha menos agua de lo que estamos habituados, y eso sin duda pone alertas que importantes. Pero cien litros en tiempos de pandemia, en que tirar la cadena significa no sé cuánto, que ducharse significa otro tanto, casi hace imposible lavar con la lavadora y olvídate de 
tener plantas en tu jardín. Con cien litros no se puede. Entonces, incluye una revisión que sin duda tiene que ver con el contexto y la territorialidad de cada parte, pero la situación es tan compleja hoy que sin duda tenemos que adecuarnos a valorar este recurso, a tomarlo con sentido común. Pero ese sentido común a la luz de las demandas sociales y de la contingencia también implica que este uso racionalizado del agua que se le impone a las personas no puede ser a la vista de que hay un privilegio para las empresas, para el desarrollo del agua para las paltas, las forestales, las celulosas y el uso indiscriminado de la minería.

Entonces, cuando hablamos de la cantidad de litros, parece una discusión incluso un tanto mezquina y absurda cuando se roba el agua en cantidades tan groseras en otros aspectos de la vida, en otras instancias. La mirada de nosotros como pueblos originarios recae en que debemos tener un uso consciente del agua; que es personal, sin duda, más en estos tiempos de crisis, pero no puede ser ésa la única toma de conciencia, cuando nuestro medio ambiente está en general siendo saqueado desde otras partes.

\section{Pregunta 2}

¿Creen ustedes posible avanzar en el reconocimiento, goce y ejercicio del derecho al agua de toda la población que habita el territorio mientras se mantenga el Código de Aguas, que la regula como una mercancía, no como un derecho humano autónomo, una garantía para otros derechos, como la vida, la salud, la alimentación?

\section{Sara Larraín}

Considerando el marco jurídico vigente, no tenemos ninguna posibilidad de asegurar el reconocimiento, goce y ejercicio del derecho al agua, dado que tenemos un Código de Aguas que, aunque la reconoce como un bien nacional de uso público, de inmediato establece la posibilidad de entregar estos derechos a los particulares. En virtud del Código de Aguas, en concordancia con lo establecido en el artículo 19 número 24 de la Constitución, se les reconoce a los particulares la propiedad sobre esos derechos. Esta conjunción entre el diseño constitucional y el diseño del Código hace bastante imposible permitir acceso, gestión y goce del agua en forma equitativa, sustentable y sobre la base del interés público. El Código, aprobado de facto por la dictadura militar, separó el agua de la tierra y creó el derecho de agua como propiedad, justamente con el objetivo político de entregar el agua a los usos más competitivos. De esta forma, son otorgados por el Estado o se accede a ellos a través del mercado de aguas; obviamente, quien no tiene posibilidades de acceder al mercado de aguas, no tiene acceso a ésta. En la actualidad, han sido otorgados en Chile casi el $80 \%$ de los derechos de aguas superficiales y más de la mitad de las aguas subterráneas. Por lo 
mismo, casi la totalidad de las aguas ya están bajo un régimen de propiedad protegido por la Constitución de 1980. Cambiar el acceso, la gestión y la utilización del agua ya privatizada implica necesariamente un cambio constitucional. Hoy, la mayor parte de las aguas superficiales y más de la mitad de las aguas subterráneas están capturadas por el mercado y el sector privado. Aquí hay un problema mayor, y si queremos generar una estructura de acceso y de gestión que asegure los derechos humanos al agua potable y el saneamiento, a las actividades de subsistencia, a la protección de las fuentes de agua, a las cuencas, a las cabeceras de cuenca, incluidos los glaciares, los humedales - que son las esponjas de reserva de agua-, hay que entrar a una «cirugía» constitucional. En consecuencia, requerimos un cambio del Código de Aguas de 1981 y un cambio de la Constitución de 1980.

Sin embargo, es posible avanzar ahora mientras desarrollamos el proceso constituyente. Durante la transición hacia la democracia se presentó una primera reforma al Código de Aguas en 1992. Su tramitación demoró trece años y fue aprobada una reforma con cambios menores en 2005. Entre 2005 y 2010, hubo decenas de proyectos de reforma presentadas por parlamentarios. Una de estas mociones, a la que aludí en la respuesta anterior (Boletín 7543-12), tuvo más viabilidad en su tramitación desde 2011, por el apoyo ciudadano y liderazgo de algunos parlamentarios, e implicaría - de aprobarse - un tremendo avance. Por lo mismo, su tramitación ha sido difícil, porque ha sido bloqueada en las distintas comisiones por intereses corporativos.

En lo fundamental, dicha reforma - que está terminando su segundo trámite constitucional- establece que el agua es un bien público, que el acceso al agua es un derecho humano que debe ser garantizado por el Estado - introducido principalmente en reformas al artículo 5- y establece prioridades de uso. Dentro de esas prioridades, establece el agua potable y el saneamiento, actividades de subsistencia, protección de las fuentes y del medio ambiente; también reconoce usos competitivos o de lucro, pero los coloca como finales dentro de la priorización. Como la concepción de esta priorización que hace la reforma está basada en criterios de función social de la propiedad, permite relativizar la propiedad a ultranza que está consagrada en el marco legal y constitucional vigente. También hay un avance en la reforma al definir la facultad del Estado de establecer reservas de agua para el uso humano y saneamiento, además de para protección de la naturaleza. En consecuencia, el Estado no estaría obligado siempre a entregar los derechos de aguas disponibles, sino que puede decir: «No, no los voy a otorgar, porque los destinaré como reservas de saneamiento para los sistemas de agua potable rural de todo el país», por ejemplo, o para sectores urbanos en los que falte esta agua, o para comunidades indígenas.

Además, esta reforma contiene regulación que permite extinguir los derechos que están acaparados por los privados y que no se estén utilizando; o caducar los derechos de aquéllos que no los han inscrito, con el objeto de especular y no pagar patente por no uso de estos derechos de agua. Respecto de esta reforma al Código de Aguas, 
también reconozco una tremenda innovación el establecimiento de usos de agua no extractivos, lo que es muy importante para, por ejemplo, las comunidades indígenas que muchas veces están manteniendo un humedal o una vertiente por usos esenciales y medicinales, y que tienen que pagar derechos de aguas porque no cuentan con una obra de captación para extraerla, una situación totalmente absurda del Código de 1981. O, por ejemplo, en áreas protegidas para la protección de la biodiversidad, donde obviamente no se va a extraer el agua. También se da en el caso de los municipios que tienen derechos de agua para conservación, paisajismo o desarrollo turístico, que tienen que pagar patente porque no están haciendo obras para extraer el agua, que es la lógica extractivista que tiene el Código. Esta reforma establece la posibilidad de usos no extractivos, que yo creo que es esencial para mantener caudales ecológicos, impedir que continúe la sobreexplotación de las cuencas y posibilitar usos múltiples.

\section{Ana Lya Uriarte}

Uno de los problemas centrales que advertimos es que el agua - mal llamado «recurso», porque es un componente de la naturaleza, un componente ambiental— ha sido ignorada en cuanto a sus tres dimensiones.

El agua tiene tres dimensiones: una primera dimensión y principal, que es su uso como provisión a las poblaciones, primera y prioritaria; también el agua tiene una dimensión ambiental, que es servir de sostén a los distintos ecosistemas; por último, está la dimensión económica, en la que podemos visualizar el agua como un insumo para el desarrollo de las actividades económicas. Naturalmente, la invisibilización de estas dimensiones se relaciona de manera directa con el Código de Aguas de 1981, que - como sabemos por la historia de su gestación, es decir, un Código nacido en dictadura - responde a una identificación con el modelo neoliberal, que transforma el agua en una mercancía, en un commodity y entrega la regulación a los mercados de agua. Los particulares, personas naturales o jurídicas, se hacen propietarios de forma gratuita y a perpetuidad, y esos derechos entran al mercado del agua. Este modelo que implementó el Código de 1981 echó por tierra el modelo del anterior Código de Aguas, que sí reconocía las otras dimensiones del agua y regulaba, desde luego, un orden jerárquico de asignación de tareas o de uso respecto del agua, y naturalmente consideraba como prioritario el de provisión a la población. Hoy, nosotros sabemos que el 90\% de los derechos de aprovechamiento de agua de carácter consuntivo aguas cuyo titular no tiene la obligación de devolverlo a un caudal- está en manos de mineras y agroexportadoras, y prácticamente el 100\% de las aguas de aprovechamiento no consuntivo - aguas utilizadas que son devueltas o retornan a un caudalse encuentran en manos de empresas transnacionales que se ocupan de las tareas de saneamiento.

En este contexto, en las condiciones constitucionales y legales actuales tenemos, 
desde luego, un problema grave con el cumplimiento de la obligación del Estado de respetar el derecho humano de acceso al agua y al saneamiento. ¿Por qué? Porque existe hoy una legislación que, interpretada en términos estrictos, legalistas, exegéticos, sin una interpretación adecuada a la vigencia de los derechos humanos, indudablemente significa que no es posible restringir o intervenir de algún modo este modelo de derechos de propiedad que determina el Código de Aguas y que, junto al artículo 19 número 24 de nuestra Constitución, propicia el que nuestra institucionalidad se sienta constreñida para tomar decisiones severas que orientarían un actuar distinto. En resumen, una interpretación restrictiva, no acorde a derechos humanos, implica un problema severo de restricción del acceso al agua por parte de la población. Sin embargo, ello no debería acaecer de esta manera, pues según el artículo 5 de nuestra Constitución, los derechos reconocidos en los tratados internacionales deben ser respetados y promovidos por nuestro ordenamiento jurídico.

\section{Samuel Yupanqui}

Sin duda, como han mencionado, el Código de Aguas es una vergüenza nacional en el ámbito internacional, ya que nos identifica como el país que privatizó el agua. Para nosotros, el Código de Aguas es un manual de saqueo, hecho para otros, para los que puedan pagar, que por lo general no somos nosotros, ni la gente de escasos recursos, ni la gente de comunidades, ni los pequeños agricultores. Sin duda, también tiene que ver con un problema fundamental, en cuanto choca con los derechos humanos, como lo que se planteó en la Asamblea de las Naciones Unidas en el año 2010 del uso del agua. Para que este derecho sea efectivo, debiese tener un orden claro de la priorización del agua, mientras que el Código lo deja al arbitrio de quien tiene más, de quien llega primero, de quien se sabe mejor la trampa, de quien entiende la trampa. Para los pueblos originarios, esto ha sido un problema fundamental, transversal, de una magnitud muy importante para nosotros. Nos afecta en el acceso a nuestras aguas ancestrales, que pasan por nuestros predios, que ya no son nuestras, pues dan acceso del uso al agua para las mineras.

Como se ve, el problema es muy grande. Además, sumado a los tratados propios de los pueblos originarios, como el Convenio 169 de la Organización Internacional del Trabajo, que establece el derecho a la consulta, requiere revisarse que este Código aborde de modo particular a los pueblos originarios y que éstos sean consultados. Por otra parte, este tipo de lógica da cuenta de una visión colonialista, de libre mercado, sobre un mal llamado «recurso», sobre un elemento primordial como es el agua; la cual tiene, además, relación con los temas de evaluación de impacto ambiental, en los que hay una interpretación muy pobre en cuanto a la cuestión antropológica del impacto ambiental, en la que por lo general no se considera a las comunidades en los estudios de evaluación. No comprenden variables antropológicas o de los pue- 
blos originarios, porque no tienen personal capacitado para para entenderlo; además, porque el Estado todavía no entiende la cosmovisión indígena. Por ejemplo, como decía la hermana Sara, hay lugares donde el agua no es para sacar, sino que cumple una función completamente diferente. Este Código no permite que existan estos sentidos.

También esto se suma a los problemas de la planificación territorial en aspectos rurales. Las comunidades son excluidas, y quien planifica a nivel nacional considera el territorio respecto de las grandes industrias, las inmobiliarias o las empresas, no respecto de las personas y comunidades que ahí habitan. Entonces, esto se suma a un problema que es puntual con el Código de Aguas, pero también con lo que, reitero, es una comprensión de un Estado extractivista, de un Estado colonial aún y un Estado que no ve más realidades que las que quiere ver y que, en eso, incumple tratados internacionales de derechos humanos, los de pueblos indígenas y los de derecho al agua.

En síntesis, creo que este Código de Aguas es un problema muy grande y que sin duda arrastra problemas más importantes para que se conjugue con otros derechos, como los derechos de los pueblos originarios, el derecho a la salud, el derecho a la alimentación: que se prioricen ciertos tipos de cultivos, los monocultivos, frente a las posibilidades que tienen los pequeños agricultores.

\section{Pregunta 3}

Hay quienes señalan que el problema fundamental para avanzar en un cambio de paradigma para la regulación del agua es la colisión entre el derecho humano al agua y el sistema de propiedad sobre los derechos de aguas. ¿Piensan que hay aquí realmente una colisión de derechos? Y si la hubiera, ¿cómo se podría resolver, a su criterio, dicha colisión? ¿Piensan que estos derechos tienen una entidad equivalente o debiera haber una prelación de usos ofunciones?

\section{Sara Larraín}

La verdad es que la colisión es evidente. Ha estado clara desde la primera reforma al Código en 1992, aprobada más de una década después en 2005, que por sus obstáculos y recortes terminó siendo una reforma superficial. Con esta segunda reforma, presentada en 2011, ya llevamos nueve años de tramitación, con obstaculizaciones permanentes. Entonces, hay sectores que no quieren, aquéllos que justamente tienen las aguas: el sector de los regantes tiene más del 70\% de las aguas superficiales en formato de derechos consuntivos; las grandes empresas hidroeléctricas, que son dueñas de los derechos no consuntivos de las aguas superficiales; y, obviamente, el empresariado minero en las regiones del norte, que posee más del $80 \%$ de las aguas, 
sobre todo en Antofagasta. Entonces acá hay un sector que se apropió de las aguas, que tiene poder y que ha obstaculizado las reformas parapetándose en este régimen, en este marco legal propietarista, y eso ha impedido que el Estado pueda establecer un régimen distinto.

Otra evidencia de que aquí hay una colisión importante de derechos es que, legalmente, lo único que le queda a la autoridad es establecer decretos de escasez hídrica y decretos de emergencia agrícola. Absurdo, completamente absurdo, sólo implica aumentar los camiones aljibes. Es claro que acá hay que resolver legal y constitucionalmente esta coalición, porque no hay equidad en los derechos. El derecho de propiedad es fundamental en el Código, se expresa en cada uno de los mecanismos: los remates de agua, el no uso de agua, cambiar como quieran el uso del agua. Por lo tanto, en la zona norte, por ejemplo, se vende una parte del agua a las mineras, se reserva otra parte y ninguna autoridad puede limitar la venta a las mineras que le darán un uso distinto al que en principio tenía. Además, como se contamina y se vuelve toxica, dicha agua debe ser confinada y ya no recargará los acuíferos, pues tiene el riesgo de que percole y contamine la cuenca aguas abajo.

Una nueva normativa constitucional debe establecer que el agua es un bien público. No un bien estatal, sino público, propiedad de todos los habitantes de la nación, no un recurso privado. En consecuencia, si se considera la entrega de derechos, deben hacerse sólo como concesión, ya que es un bien social. Sólo después de satisfacer los derechos humanos, el derecho a la alimentación, la protección de las cuencas. En tanto bien público, se puede usar y gozar, pero no es posible establecer propiedad o disposición.

Se debe plantear, además, una gestión integrada de las cuencas. En la actualidad, por ejemplo, el Estado desde el nivel central concede derechos sin preguntarle a la comunidad, y terminan gestionando las aguas y las cuencas las juntas de vigilancia, constituidas por los propietarios de derechos de agua. El Estado subsidiario solo puede intervenir si la junta de vigilancia tiene problemas o en casos de escasez. No están representados ni el municipio ni los que viven en la orilla. Si no tienen derechos de agua, no están. Entonces, aquí hay que cambiar esta gestión también privatista de la cuenca y, por lo tanto, hay que establecer una gestión integrada del agua y de las cuencas, desde el nacimiento hasta la desembocadura, que sea democrática, una gestión en la que participen las juntas de vecinos, los municipios, no puede ser una gestión monopolizada por los propietarios de derechos de agua. Esto es completamente absurdo y contradice la evidencia científica sobre funciones múltiples del agua y los servicios ambientales que proveen las cuencas a la sociedad y los ecosistemas. Entonces, una gestión integrada de cuencas implica que tenemos que cambiar el tema de las organizaciones de usuarios, porque aquí esto tiene que ampliarse, tiene que haber una gestión integrada y democrática del agua y de las cuencas, que son bienes públicos. El Estado, a través del Ministerio de Bienes Nacionales, hace varias décadas 
estableció que las cuencas y las orillas de río son bienes públicos, pero resulta que el agua no se puede gestionar ni por la autoridad, ni por los vecinos, sino sólo por los propietarios de derechos de agua.

Por ello, considero que requerimos un cambio estructural, y reforzar lo que expresó Samuel. El Código de Aguas chileno es el único que ha privatizado a perpetuidad las aguas y, por lo tanto, aquí se requiere una cirugía mayor. Tenemos que hacer cambios de fondo, porque la colisión de derechos no tiene ninguna posibilidad de resolverse hoy desde una perspectiva de los derechos, del bien público o de la prelación de usos. Aquí hay que reforzar el bien público, estableciéndolo y blindándolo legal y constitucionalmente. El derecho humano también hay que establecerlo legal y constitucionalmente. La prelación de usos hay que establecerla legal y constitucionalmente. También hay que poner los principios sobre forma de gestión pública y gobernanza en la ley y en la Constitución. Por lo tanto, el desafío es mayor.

\section{Ana Lya Uriarte}

Respecto de la colisión, quisiera señalar, para partir, que hoy hay más derechos de agua otorgados, de manera gratuita y a perpetuidad, que el agua existente en el país. Entonces, antes que todo, hay que pensar que la legalidad vigente nos pone ante una situación estructural gravísima.

$\mathrm{Si}$ atendemos al enunciado constitucional de los derechos fundamentales, en el que el derecho de propiedad tiene una asignación valórica y de protección que actúa en el mismo nivel y rango que el derecho a la vida, por ejemplo, y a todo lo que se requiere para que ella se sostenga, claramente tenemos una colisión, pues el derecho humano al agua, como no tiene un reconocimiento constitucional expreso, lo podemos subsumir en aquéllos que son necesarios para mantener la vida. Sin embargo, creo que sigue siendo posible, aun en el marco actual, intervenir. Desde luego, si tenemos en cuenta el artículo 5 de nuestra Constitución, que establece que el ejercicio de la soberanía reconoce como limitación el respeto a los derechos esenciales que emanan de la naturaleza humana, y que es deber de los órganos del Estado respetar y promover estos derechos, garantizados por la Constitución, así como por los tratados internacionales ratificados por Chile y que se encuentren vigentes, diversos organismos dependientes del Ministerio de Agricultura como del Ministerio de Obras Públicas y otros servicios relacionados tendrían mecanismos para, por ejemplo, restringir ciertas autorizaciones o evitar conceder nuevas autorizaciones, de manera de hacer frente a la crisis en que hoy nos encontramos y de la que dan cuenta los miles de chilenos que no tienen acceso al agua.

Sin embargo, y a pesar de que pienso que hay espacios de intervención hoy, creo que la solución definitiva viene de la mano de un cambio constitucional, en el cual el agua efectivamente sea reconocida como un bien nacional de uso público, con las 
consecuencias que se derivan de ese reconocimiento constitucional. Si bien el Código de Aguas actual hace una nominación respecto del agua en esos términos, ello no sirve si no tiene un rango constitucional, en el cual, desde la lógica de la integración de la interpretación normativa constitucional, esta conceptualización pase a tener un peso suficiente como para enfrentar al derecho de propiedad, dando prioridad a la provisión de poblaciones como garantía de un derecho humano, como es el de acceso al agua potable y al saneamiento. Una nueva Constitución debe considerar el reconocimiento del derecho al agua como un bien nacional de uso público y reconocer, además, las distintas dimensiones del agua, de manera que también tengamos más cuidado o protección de nuestro medio ambiente, cuestión que hace sinergia con mejores estados de salud, como se ha señalado, por la vinculación que existe entre pandemias o creación de virus de distinto tipo con el tema de combate al cambio climático. Se trata de cambiar la lógica de comprensión de este sistema, eliminar la lógica neoliberal de la privatización de los derechos del agua en el sentido de entregar propiedad, reemplazándola por un sistema que favorezca un mejor modo de vida, una mejor vida, una mejor manera de relacionarnos con la naturaleza y proteger la vida de las personas más vulnerables, para buscar, de esta manera, una relación más equilibrada dentro de nuestra sociedad en condiciones de mayor igualdad.

\section{Samuel Yupanqui}

No sé si quiero ahondar más en lo que se ha dicho, pero concuerdo plenamente en que esto tiene que apuntar a un resguardo mayor del derecho del agua como un derecho humano, y con sus respectivas priorizaciones, según lo que establece la misma Constitución en su artículo 5, inciso segundo, de que Chile va a suscribir los tratados internacionales de derechos humanos.

Voy a abordar la parte de la pregunta que se refiere a un cambio de paradigma, $y$ ahí es donde creo que nosotros, primero, estamos en un momento propicio y fértil para iniciar este tipo de diálogo. En esa misma lógica, a veces creo que las respuestas, si bien pueden tener algo de innovador en cuanto buscan soluciones a problemáticas, desde nuestra perspectiva de los pueblos originarios andinos, nuestra concepción del tiempo, cuando decimos Pachamama, no solo hablamos de la Madre Tierra. Pacha es tiempo y también espacio. Entonces, es también esa mirada que implica para la sociedad volver a entender cosas que son primigenias para nosotros. Los incas tienen su pacarina, su lugar de origen, en el lago Titicaca. Entonces, la pacarina es donde se origina la vida, y donde se origina la vida para mis antepasados, para mi pueblo, es en un lago, es en el agua, es en el lago Titicaca. De ahí viene la vida. La pacarina puede ser lagos, puede ser el mar, puede ser volcanes, puede ser montañas, pero nuestras energías creadoras se encuentran en la naturaleza. Se encuentran en estos espacios que son los que dan la vida: el agua, la tierra. 
Es esencial y básico, incluso puede tener una explicación científica: la vida parte en el agua. Entonces, hay que entender el agua no solo como recurso, sino como un complemento necesario, como algo básico para la vida, como algo que no puede ser apropiado. En esa misma lógica, aparte de esto de las pacarinas que les comenté, está nuestra relación ceremonial primigenia y más básica, que son los reconocimientos que hacemos a través de nuestras ceremonias, de nuestra espiritualidad, con el agua. Tenemos fiestas concretas o ceremonias particulares, como el Unu Raymi, ceremonias para el agua. Estos diálogos que nosotros establecemos a través de las ceremonias sirven para establecer el equilibrio, el diálogo, entender la naturaleza, y creo que en parte lo que nos pasa hoy día, lo que le pasa a la sociedad, lo que le pasa al Estado, es que no establecemos el diálogo con la naturaleza. No sabemos escucharla. Tenemos las señales al lado, como que el desierto está avanzando. Está llegando a las puertas de Santiago y no leemos esos símbolos. Con esto no me refiero a que tengamos que ser machi o yatiri. Me refiero a observar elementos simples que nos deberían conmover, como es que se seque la cuenca de un río, como que familias no tengan acceso al agua. Entonces, desde ese punto de vista, creo que hay que apuntar a un cambio constitucional, que sea estructural y que tenga que ver con procesos de educación también. Por eso para nosotros es muy complejo hablar de estos temas por separado, porque se incluye la vida, el respeto a la naturaleza, nuestra comprensión del entorno, de las fuerzas de la naturaleza, de los espíritus, donde están alojados nuestros antepasados, tiene que ver con procesos educativos. Tiene que ver con procesos transformadores, y ahí es que quizás muchas de las respuestas también se encuentran mirando nuestro pasado, mirando nuestras raíces, mirando nuestras conexiones más primigenias que hemos tenido con el agua, que es de donde venimos. Creo que algo que cae del cielo y que nace de la tierra no es para que sea sólo de unos pocos, ¿no?

\section{Pregunta 4 (pregunta del público)}

Cuando se señala que somos el único país que ha privatizado el agua y que eso debe ser modificado en la Constitución, ¿a qué se refieren? ¿A suprimir los derechos de agua propiamente tales, o a que la distribución la haga no una empresa privada, sino una empresa estatal, y que por esa vía se resuelva este problema? ¿Es posible mantener el actual sistema de aguas, pero modificando la Constitución para establecer prioridades en el derecho al uso?

\section{Sara Larraín}

Es cierto que Chile es el único país que tiene establecido derechos de propiedad privados sobre las aguas, no hay otro. Hay algunos otros marcos legales en los cuales se entrega por un cierto periodo derechos sobre una cierta cantidad de agua, lo que se 
va revisando, pero siempre hay una atribución del ente público que puede revisar, que puede reasignar, que considere siempre el interés general de la nación.

En este contexto, en Chile el cambio debería ser que las aguas tengan un estatus blindado de bienes públicos, no necesariamente bienes estatales, porque consideramos que el paradigma de gestión de este bien público no puede quedar bajo la autoridad del Estado sin que las decisiones sean de verdad compartidas, con la prioritaria incidencia de los territorios, las comunidades en los territorios, que consideren los usos ancestrales, la información de la ciencia y las prioridades de desarrollo regional y de los habitantes de cada cuenca; es decir, las prioridades que establezca la sociedad local en su conjunto. No pensamos que la gestión de las aguas tenga que estar solo bajo el dominio del Estado, nosotros creemos que la gestión de las aguas tiene que estar en una gobernanza democrática, participativa, en la cual se priorice la decisión de los actores del territorio.

La experiencia que se ha visto en la gestión estatal de las aguas no resuelve los problemas de las comunidades locales y menos los ambientales. Hemos visto que, en regímenes solo estatales, los Estados, muchas veces por la obsesión del crecimiento del PIB, priorizan el derecho del inversionista por sobre los derechos de las comunidades locales. En el caso de Chile, se ha visto que muchas veces el Estado entrega derechos a un inversionista extranjero por sobre incluso los derechos de aguas que poseen los campesinos o los indígenas en un territorio local. Por lo tanto, creemos que la gobernanza de las aguas debiera ser una gobernanza pública, no necesariamente solo de los agentes del Estado; ahí yo creo que hay una gran diferencia. Se requiere un cambio de paradigma, porque se debe gestionar en conjunto desde la perspectiva de las regiones y los territorios, desde la perspectiva de bienes públicos, que tienen una lógica ecosistémica, que considera para la gestión de las cuencas el ciclo de agua. Por lo tanto, hay que considerar la capacidad de carga, posibilidades de uso, servicios ambientales, incluso más allá del agua misma: cuáles son las especies arbóreas presentes, cuál es la temperatura en esa cuenca. También se debe adaptar la gestión de la cuenca a fenómenos globales, como el calentamiento global. Por lo mismo, debiera haber un modelo de gestión pública, pero de tipo comunitario, participativo, democrático, por cuenca.

\section{Ana Lya Uriarte}

Una calificación constitucional de bien nacional de uso público de las aguas es incompatible con la mantención del actual sistema de derechos de propiedad. La denominación de bien nacional de uso público también implica el tema de la gestión del agua, el cual va a tener que quedar establecido en la Constitución, para asegurar la gestión integrada de la cuenca hidrográfica. Ésta es la unidad de gestión por excelencia para hacer gestión ambiental. La gestión integrada de cuencas hidrográficas 
incluye naturalmente las vocaciones de los territorios y la participación de quienes los habitan.

\section{Samuel Yupanqui}

Es fundamental ver desde dónde estoy posicionado yo, ¿no? El uso y el goce de las aguas en cuanto al derecho ancestral que los pueblos originarios. No solamente queremos que las aguas las administre el Estado. En cuanto a nuestro territorio, también creemos que el principio de la autodeterminación incluye la administración de los recursos naturales que ahí yacen. En esa lógica, creo que es muy importante el énfasis que puse antes, que este Código de Aguas nunca ha sido consultado con las comunidades y los pueblos originarios. Pero, sin duda, la Constitución nos pone un desafío más grande como pueblos originarios, que es acercarnos a la administración de nuestros propios recursos, de nuestro propio ecosistema, de nuestro propio territorio. Creo que es un derecho al que se hace mención quizás con esto de la gestión de las cuencas hidrográficas que deben tener las comunidades, ya que no puede ser que las personas que viven ahí estén escindidas del «recurso» del agua, así como del resto de recursos que están dentro de su territorio. El agua sin duda tiene que ser priorizada como un bien de uso público, pero también debe recoger la historia, nuestra memoria, los lugares que ocupamos, cómo la hemos resguardado. Por lo mismo, el agua es parte de nuestros territorios y nuestros territorios deben tener la autodeterminación que ello implica: que sean los mismos pueblos originarios los que decidan también ese derecho ancestral a la administración, que, por lo demás, ha estado siempre en alguna medida en los territorios.

\section{Pregunta 5 (pregunta del público)}

¿En qué capítulo de una nueva constitución se colocaría el agua como bien común y se garantizaría el derecho a su acceso?

\section{Sara Larraín}

Es una excelente pregunta, porque creo que cada uno de nosotros está viendo cómo conciliar los desafíos históricos, las lecciones de la crisis social y ambiental en la cual estamos, y al mismo tiempo hacernos cargo de las estructuras tradicionales de las constituciones y de los marcos jurídicos institucionales. En un ejercicio para una nueva carta fundamental, el tema del agua tiene que estar presente en el ámbito de los derechos; debe ser parte del articulado vinculado al tema de los derechos en la medida que, si lo establecemos como un bien público, va a implicar un derecho de todos sobre estas aguas. Dentro de eso explicaremos el derecho humano, por estar vinculado al derecho a la vida, al derecho a la salud, al derecho a la alimentación, 
etcétera. Por lo tanto, hay una redacción y toda una formulación de la perspectiva de los derechos que tiene que estar en la Constitución.

No obstante, si lo dejamos solamente en los derechos, pero no en el articulado relativo a los bienes y el acceso a los bienes y cómo vamos a conceptualizar los bienes públicos, también estaríamos en un problema, porque dejaríamos un vacío. Debemos referirnos al agua y a otros bienes esenciales. Hay que abordar los bienes comunes, de cómo se accede a estos, cómo se usan, cómo se gozan, cuáles son las condiciones de uso, etcétera. Por último, también en los artículos vinculados a las formas de gestión y la gobernanza. ¿Cómo va a ser? ¿Va a ser por parte de los territorios? ¿Va a ser a través de las cuencas? ¿Lo va a hacer el Estado a través de un ministerio, a través de una dirección bajo el Ministerio de Obras Públicas? ¿Por qué el agua está bajo el Ministerio de Obras Públicas? ¿Qué tiene que ver el agua con las obras públicas? Las cuencas no son un tubo de cemento, las cuencas son ecosistemas que proveen un servicio de aguas, proveen un servicio de temperatura, proveen servicio de bosques, etcétera. Entonces, el tema de la gobernanza tiene que ver con la conceptualización de este bien público, de cómo va a ser esta gestión y quiénes van a hacer esta gestión.

Nosotros entendemos que no es lo mismo el Estado que lo público. En un nuevo paradigma de gestión de lo ambiental en términos democráticos, en términos de inclusión, en términos de participación ciudadana y de básica autonomía territorial y descentralización, creemos que en la gobernanza de los bienes públicos tiene que quedar meridianamente claro cuál es la definición de la gestión pública, y eso lo trasladaremos después a la gestión integrada de cuencas, quiénes participan, cuál va ser el rol del agente del Estado, cuál va a ser el rol de las comunidades, cuál va a ser el rol de las empresas y de la autoridad local. Pero, al menos los derechos, los principios sobre los bienes y los principios sobre gobernanza tienen que estar establecidos en la Constitución.

Por último, hay un tema específico que se debe considerar: las juntas de vigilancia como organizaciones de usuarios que deben reformarse en el Código, pero a partir de los principios de gobernanza que se establezcan en la Constitución. Claramente, las juntas de vigilancia son clubes de propietarios de derechos de aguas y, por lo tanto, es un derecho, un voto; así que un campesino que tiene un litro por segundo «sonó», porque tiene que enfrentarse a otros que tienen cien litros por segundo o más y, por lo tanto, su voto para el turno que le toque o para la gestión, etcétera, no tiene ninguna posibilidad. Además, muchos campesinos no han perfeccionado sus derechos: los tienen en tejas, los tienen en acciones, no en litros por segundo; otros ni siquiera los han regularizado y, por lo tanto, tampoco les permiten entrar en la junta de vigilancia y participar en la gestión. Entonces, dentro de la Constitución, en el tema de la gobernanza, tenemos que ver quiénes son los que gestionan, quiénes son los que gobiernan estos bienes públicos. 


\section{Ana Lya Uriarte}

Sólo dos alcances. Quisiera destacar una frase de Samuel, que yo creo que es muy inspiradora. La tomo, la quiero repetir porque me parece extraordinaria: «Algo que cae del cielo y nace de la tierra». Eso es el agua y, en consecuencia, apropiarse del agua es como apropiarse del aire. La verdad es que mirar el tema a partir de esa frase poética es muy inspirador para lo que estamos conversando.

Quisiera solo complementar el hecho de que sin duda una nueva constitución para Chile tiene que consignar principios. Esos principios tienen que ver con cómo nos vamos a relacionar entre nosotros como personas y cómo nos vamos a relacionar con la naturaleza. Es dentro de esta conceptualización que naturalmente tiene que haber una definición de país, de personas, respecto de cómo vamos a enfrentar el componente ambiental agua en el futuro. Si en definitiva queremos que siga siendo un recurso, con lo cual lo asociamos a un bien económico, o si queremos que sea un componente ambiental, que va a requerir, en consecuencia, otras definiciones muy distintas a las que hemos conocido hasta ahora, que incluyen, desde luego, la visión de los pueblos originarios, que, por lo demás, no es una ni unívoca, hay puntos de coincidencia, como el respeto que tienen los distintos pueblos originarios por nuestros componentes ambientales.

\section{Samuel Yupanqui}

Cuando hablamos de entender el agua como un derecho, sin duda que no va a pasar solamente por el Ministerio de Obras Públicas, por la Administración o la legislación, sino que también tiene que ver con procesos educativos, tiene que ver con cómo el Estado va cambiando una visión, cómo nos podemos ir relacionando con nuevos componentes que quizás antes estaban ocultos, como los paradigmas, las formas de comprensión y de entender el mundo, la ciencia, la tecnología y la filosofía de los pueblos originarios, por ejemplo. Eso me imagino que tiene que ver también con procesos que son más amplios que solo estar vinculado con lo que sea propiamente la legislación del agua. Por ejemplo, este país que sueño implica por ejemplo que haya medios de comunicación que tengan una labor más fuerte en la educación; creo que también implicaría que los establecimientos educacionales hablen de los pueblos originarios. Yo soy de pueblos originarios y prácticamente nunca me hablaron de ellos, para lo único que hablan de pueblos originarios es para hacernos bullying.

Es un proceso mucho más complejo. Implica, por ejemplo, un Ministerio de Medio Ambiente más comprometido en una política que puede salvar nuestros recursos, ya que estamos a tiempo de generar una educación profunda hacia la población. Se trata de cambiar de paradigma a una mirada holística, una propuesta que implica una apertura de corazón, de mente y de disposición al diálogo muy amplia. 


\section{Palabras de cierre}

Agradecemos a nuestros panelistas por sus ilustradoras presentaciones, las que quedarán plasmadas en el Anuario de Derechos Humanos del Centro de Derechos Humanos de la Facultad de Derecho de la Universidad de Chile, a disposición y para el conocimiento de todos los chilenos y quienes estén interesados en conocer la compleja situación que nos aqueja respecto de la justicia hídrica en nuestro país.

\section{Nota}

Las entrevistas de la sección Debate se efectuaron en el marco del ciclo de conversaciones «Derechos Humanos en Tiempos de Pandemia», que organizó el Centro de Derechos Humanos durante junio de 2020.

\section{Sobre los entrevistados}

SARA LARraín es ecóloga, directora ejecutiva de la fundación Chile Sustentable. Su trabajo se ha orientado al diseño e implementación de propuestas de política pública para la sustentabilidad en el uso de ecosistemas y recursos naturales, de manera de satisfacer las necesidades de las generaciones presentes sin comprometer la capacidad de satisfacción de necesidades de las generaciones futuras.

Ana Lya Uriarte es docente de la Facultad de Derecho de la Universidad de Chile. Integrante del Centro de Derecho Ambiental de la misma casa de estudios. Primera ministra del Ministerio del Medio Ambiente, a cargo de la instalación, diseño e instalación del organismo. Desarrolla su trabajo como académica con énfasis en el ámbito del derecho al agua.

SAMUel YUPANQUi es sociólogo, presidente de la asociación indígena aymaraquechua Jach'a Marka. Miembro del Consejo Metropolitano de Pueblos Andinos. Coordinador del Instituto de Arte, Cultura, Ciencia y Tecnología Indígena de Santiago. Integrante de la Mesa Regional Indígena de Santiago. Es miembro del pueblo quechua. 
El Anuario de Derechos Humanos es una publicación semestral de referencia y consulta en materia de derechos humanos y campos afines. Busca ser un espacio de discusión de los temas centrales en el ámbito nacional e internacional sobre derechos humanos. Es publicado desde 2005 por el Centro de Derechos Humanos de la Facultad de Derecho de la Universidad de Chile.

\author{
EDITORA \\ Claudia Iriarte Rivas \\ ciriarter@derecho.uchile.cl \\ SITIO WEB \\ anuariocdh.uchile.cl \\ CORREO ELECTRÓNICO \\ anuario-cdh@derecho.uchile.cl \\ LICENCIA DE ESTE ARTÍCULO \\ Creative Commons Atribución Compartir Igual 4.o Internacional
}

\author{
\% \\ La edición de textos, el diseño editorial \\ y la conversión a formatos electrónicos de este artículo \\ estuvieron a cargo de Tipográfica \\ (www.tipografica.io)
}

